\title{
A comparison of transversus abdominis plane block with quadratus lumborum block for post-operative analgesia in abdominal hysterectomy: a retrospective observational study
}

\author{
Sumit Kumar Gupta ${ }^{1}$, Ritu Grewal ${ }^{1}$, Sirisha Anne ${ }^{2}$, Arpit Garg ${ }^{1 *}$
}

\begin{abstract}
${ }^{1}$ Department of Anaesthesiology and Critical Care, ${ }^{2}$ Department of Obstetrics and Gynaecology, Command Hospital, Lucknow, Uttar Pradesh, India
\end{abstract}

Received: 11 March 2021

Revised: 07 April 2021

Accepted: 09 April 2021

\section{*Correspondence:}

Dr. Arpit Garg

E-mail: gargarpit81@gmail.com

Copyright: (c) the author(s), publisher and licensee Medip Academy. This is an open-access article distributed under the terms of the Creative Commons Attribution Non-Commercial License, which permits unrestricted non-commercial use, distribution, and reproduction in any medium, provided the original work is properly cited.

\section{ABSTRACT}

Background: Abdominal hysterectomy is the most common surgery performed in Indian Women. Recent advances in Regional Anaesthesia especially ultrasonography-guided truncal blocks for postoperative analgesia are now being used for patient comfort and faster times for discharge of the patients. This study compares the ultrasonographic guided transversus abdominis plane block and quadratus lumborum blocks for patients undergoing abdominal hysterectomy under general anaesthesia. Aim of the study was to compare the efficacy of transversus abdominis plane block and quadratus lumborum blocks in patients undergoing abdominal hysterectomy.

Methods: A retrospective observational study of prospectively collected data was performed. A total of 111 patients of American Society of Anesthesiologists (ASA) II and III gradings were enrolled in the study who had received either transversus abdominis plane block or quadratus lumborum blocks. Visual analog scale (VAS) scores and use of rescue analgesia was studied between the two groups. The data obtained were analysed using the students t-test and Mann Whitney U Test.

Results: The demographic profile was similar between the 2 groups. The study showed that patients who received the quadratus lumborum block had a greater analgesia after 6 hours and had lower analgesic requirements compared to those who received transversus abdominis block (TAP) block. TAP block was however effective in the initial postoperative period.

Conclusions: In patients undergoing abdominal hysterectomy quadratus lumborum block may be preferred over TAP block for post-operative analgesia.

Keywords: Transverse abdominis plane block, Post op analgesia, Quadratus lumborum block

\section{INTRODUCTION}

Total abdominal hysterectomy is the most common non obstetric major surgical procedure performed in the Indian women. ${ }^{1}$ It is usually performed through laparotomy under general anaesthesia with an average duration of hospital stay from 2 to 11 days. $^{2}$ It is also performed under central neuraxial blocks. The use of peri operative regional anaesthesia during elective surgeries has been shown to reduce discomfort, help in early recovery, better ambulation and the need for opioids post operatively. ${ }^{3}$ Epidural analgesia has been traditionally being used for these patients, however they have got a side effect of their own which may cause discomfort to the patients. ${ }^{4}$ With the advent of use of ultrasonography in the operating room many new modalities of regional analgesia can be provided to these patients. We compare two such modalities transversus abdominis block (TAP) and quadratus lumborum block (QLB) in this study. The TAP block has been extensively used in gynaecological 
surgeries. ${ }^{5,6}$ QLB is a more recent addition in the family of truncal blocks, first described by Blanco. ${ }^{7}$ The ultrasonographically assisted QLB is now used for abdominal surgeries in all age groups. ${ }^{8}$ Our study aims to compare the effectiveness of TAP block with the QLB block in patients undergoing total abdominal hysterectomy so as to provide the patients with a more effective analgesia technique in the post-operative period.

\section{METHODS}

This study is a retrospective analysis of data of patients who have undergone total abdominal hysterectomy under general anaesthesia at our institution Command Hospital, Lucknow which is a tertiary care hospital in central India. The data was prospectively collected between 01 August 2018 and 01 March 2020. The inclusion criteria for patients were all patients who underwent total abdominal hysterectomy (TAH).The patients who underwent laparoscopic or vaginal hysterectomies were excluded from the study.

The other exclusion criteria were patient refusal, a known history of allergy to opiates, amide local anaesthetics and non-steroidal anti-inflammatory drugs, any coagulation derangements and bleeding disorders, patients with skin infections at site of the blocks, patients having any cardiovascular, pulmonary or neurological diseases were excluded from the study. Obese patients with body mass index $(\mathrm{BMI})>30 \mathrm{~kg} / \mathrm{m}^{2}$ and transversus abdominis plane deeper than 07 centimetres from the skin were excluded from the study due to ultrasonic imaging limitations.

Sample size for the study was calculated based on the differences in the total rescue analgesia requirements of tramadol in our pilot study that is $4 \mathrm{mg}$ of tramadol, alpha error of 0.05 , beta error of 0.2 and power of study of $80 \%$. A total of 28 patients were required in each group. However, as the study was observational and over a long duration hence 50 patients in each group were used for the study. Patients were randomized on odd/even basis in the two subgroups to receive the blocks. A preanaesthetic evaluation of the patient for TAH was done. The patients were explained about visual analogue scale for pain $(0$ no pain, 10 worst pain imaginable) in their language. Patients were administered standardized GA with IV fentanyl 2 $\mathrm{mcg} / \mathrm{kg}$ and $20 \mathrm{mg} / \mathrm{kg}$ paracetamol. Just before extubation the patients received a TAP block which was ultrasound guided or ultrasound guided quadratus lumborum block type 2 with $2 \mathrm{mg} / \mathrm{kg}$ of $0.5 \%$ bupivacaine plain diluted to twice its volume. The blocks were administered in equal volumes at both side. After the surgery the patients were shifted to the ward and were observed for pain. This is recorded by a scale with 0 to $100 \mathrm{~mm}$ markings.

\section{Procedure for TAP block}

The patient is placed in supine position. Preparation of skin was done with povidine iodine, sterile drapes are applied. A linear ultrasonography (USG) probe of 6-12 $\mathrm{MHz}$
(Sonosite Edge II, Fujifilm Sonosite Inc) range was placed on the anterolateral abdominal wall, just cephalad to the iliac crest level where the 3 muscle layers (external oblique, internal oblique and transversus abdominis) are identified as a distinct layer (Figure 1). After identification of transversus abdominis neurofascial plane between the internal oblique muscle and transversus abdominis muscle, the USG probe was moved posterolaterally to lie between the costal margin and iliac crest across the mid axillary line. The appropriate depth and gain of the probe were adjusted to optimize the image of the abdominal wall muscles and the underlying peritoneal cavity. The target was the fascial plane between the internal oblique and the transversus abdominis muscle approximately in the mid axillary line. Approximately between 40 and $50 \mathrm{ml}$ of the total drug volume for the block (as per patient weight) in appropriate dilution was deposited in the transversus abdominis plane under ultrasound guidance on both the sides.

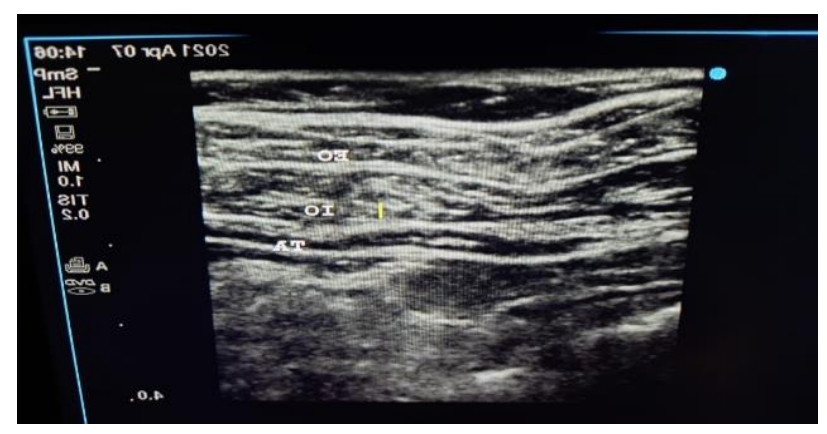

Figure 1: Transversus abdominis plane block.

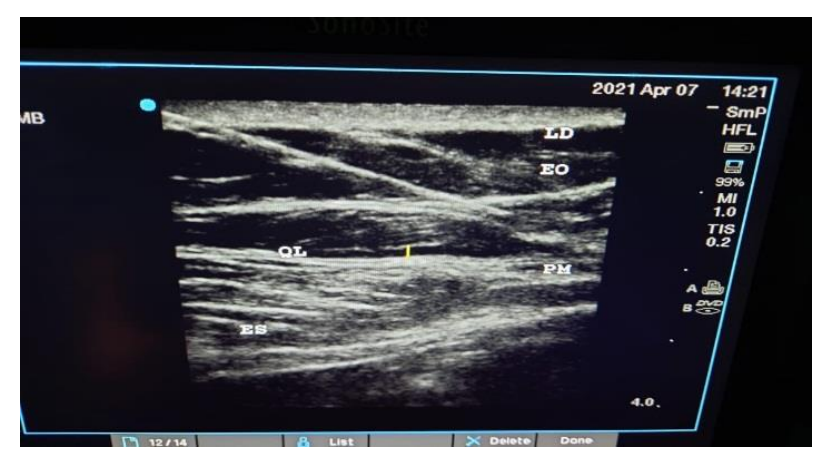

Figure 2: Quadratus lumborum block.

\section{Procedure for quadratus lumborum block QLB type 2 (posterior approach)}

Quadratus lumborum blocks have been described of four types depending upon the approaches used. QLB type 2 is the safest of them all and easy to administer in one single lateral position of the patient pre extubation. For QLB type 2 group the posterior approach is used. A wedge is placed under the buttocks. The transducer was put at the level of anterior superior iliac spine and moved upwards to visualize all the three muscles of the abdominal wall (Figure 2). Then the transducer probe was moved posteriorly till the lumbar interfascial covering the 
paraspinal muscle between the latismus dorsi and the quadratus lumborum muscle can be made out. A 22 gauge spinal needle was also moved anterolaterally to posteromedially to enter thoracolumbar fascia middle layer. The procedure is repeated on the other side. $0.5 \%$ bupivacaine $2 \mathrm{ml} / \mathrm{kg}$ after appropriate dilution is injected on each side.

Injection tramadol $2 \mathrm{mg} / \mathrm{kg}$ was given as rescue analgesia if visual analog scale (VAS) score $>35 \mathrm{~mm}$. The outcome was assessed from time of administration of the drug and the visual analogue score was assessed for pain at rest at an interval of $0,2,4,6,12$ and 24 hours.

The data obtained was analysed using statistical package for the social sciences (SPSS) software (version 17.0,
Chicago, IL, USA). The data was expressed as continuous variables as mean $( \pm \mathrm{SD})$ value. The differences in continuous parameters between the two groups was analysed using unpaired students $t$ test. Mann Whitney U test was applied for non-parametric data. A probability value (" $p$ " value) was used to determine the level of significance, $\mathrm{p}$ value $<0.5$ was considered as significant and $p$ value $<0.1$ was considered as highly significant.

\section{RESULTS}

111 patients were considered for the study. However 11 patients were not meeting the inclusion criteria mainly because of old age and comorbid conditions as well as some inadvertent protocol violations as shown in Figure 3.

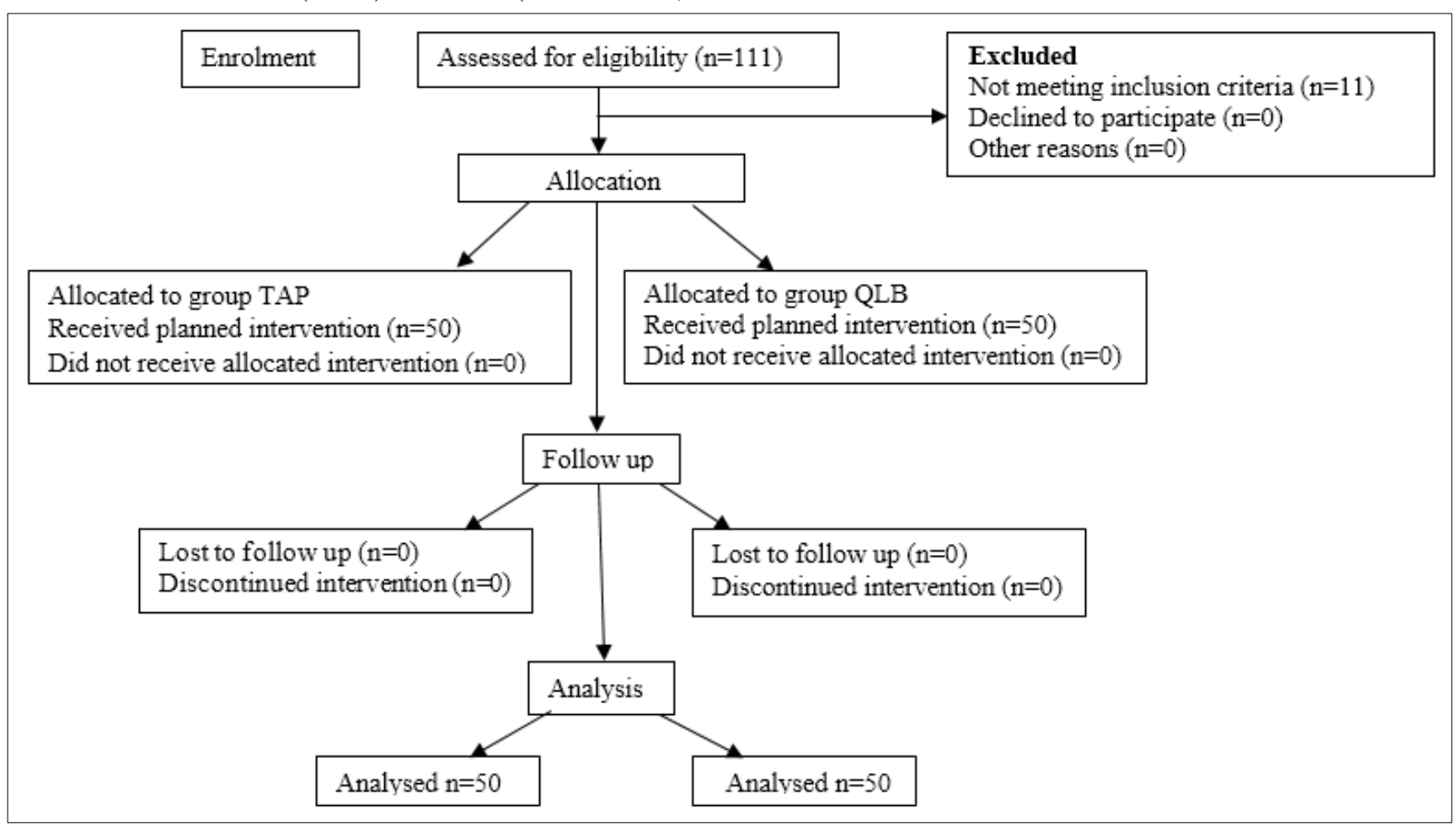

Figure 3: Chart of patient enrolment.

Out of these 100 patients 50 patients were allocated each to TAP block group and QLB group. These patients were given as per odd/even basis either TAP block or QLB. Post op analgesia was analysed as per visual analogue score and requirement of opioids. The results were then tabulated and analysed.

The present study suggested the mean $( \pm \mathrm{SD})$ age of the TAP group was $57.7( \pm 3.4)$ years and mean $( \pm$ SD) age of the QLB group was $59.7( \pm 3.5)$ years which was comparable (Table 1). Average weight of the patients in TAP block group was $68.8 \mathrm{~kg}$ whereas in QLB group was $70.2 \mathrm{~kg}$, which was also comparable in both groups. ASA (II/III) status of patients in TAP block group was 43/7 and 41/9 in TAP block group and QLB group respectively. These both values also were in comparable range (Figure 4).
Table 1: Demographic profile and operative data of the two groups (mean $\pm \mathrm{SD})$.

\begin{tabular}{|llll|}
\hline $\begin{array}{l}\text { Group } \\
\text { demographic } \\
\text { parameter }\end{array}$ & $\begin{array}{l}\text { TAP } \\
(\mathbf{n = 5 0})\end{array}$ & $\begin{array}{l}\text { QLB2 } \\
(\mathbf{n = 5 0})\end{array}$ & $\begin{array}{l}\mathbf{P} \\
\text { value }\end{array}$ \\
\hline Age & $59.9(3.4)$ & $57.7(3.5)$ & 0.23 \\
\hline Height & $147.8(7.4)$ & $151.2(6.8)$ & 0.10 \\
\hline Weight & $68.8(3.6)$ & $70.2(4.3)$ & 0.42 \\
\hline $\begin{array}{l}\text { ASA status } \\
\text { II/III }\end{array}$ & $43 / 7$ & $41 / 9$ & 0.79 \\
\hline $\begin{array}{l}\text { Duration of } \\
\text { surgery (min) } \\
\text { excluding } \\
\text { block time }\end{array}$ & $\begin{array}{l}104.32 \\
(10.6)\end{array}$ & $\begin{array}{l}102.22 \\
(11.2)\end{array}$ \\
\hline
\end{tabular}




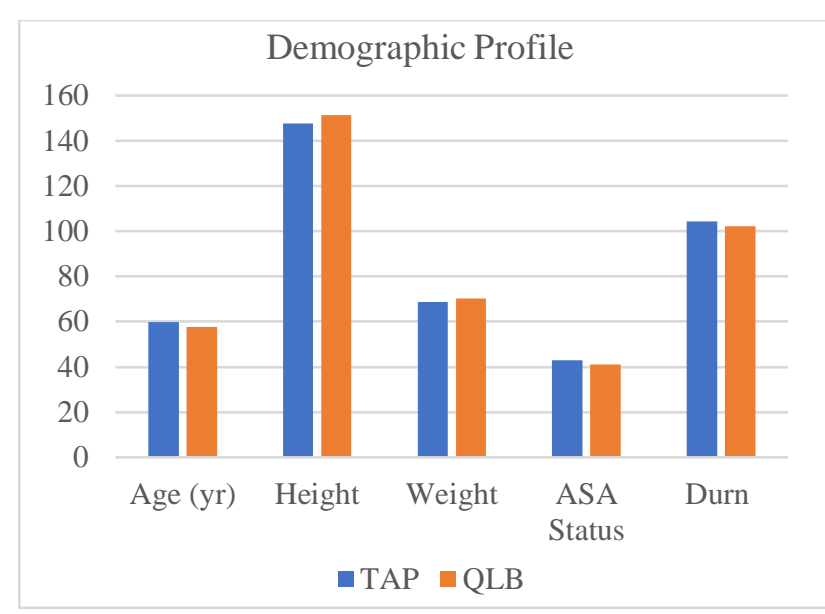

Figure 4: Demographic profile of the patients.

The visual analogue scale of TAP and QLB groups was compared at $0,2,4,6,12$, and 24 hours post operatively (Table 2). Median scale of the TAP group at $0,2,4,6,12$ and 24 hours was $0 \mathrm{~mm}, 22 \mathrm{~mm}, 27 \mathrm{~mm}, 25 \mathrm{~mm}, 26 \mathrm{~mm}$ and $23 \mathrm{~mm}$ respectively and median score of the QLB group at $0,2,4,6,12,24$ hours was $0 \mathrm{~mm}, 22 \mathrm{~mm}, 22 \mathrm{~mm}$, $17 \mathrm{~mm}, 18 \mathrm{~mm}, 15 \mathrm{~mm}$. Mann Whitney U test was applied as the data was non parametric. $\mathrm{P}$ value of $0.968,0.205$, $0.312,0.09,0.03$ and 0.01 was obtained for $0,2,4,6,12$ and 24 hours respectively (Table 2).

Table 2: Median VAS score of TAP and QLB groups.

\begin{tabular}{|llll|}
\hline $\begin{array}{l}\text { VAS } \\
\text { (hours) }\end{array}$ & $\begin{array}{l}\text { Group TAP } \\
(\mathbf{m m})\end{array}$ & $\begin{array}{l}\text { Group QLB } \\
(\mathbf{m m})\end{array}$ & P value \\
\hline $\mathbf{0}$ & 0 & 0 & 0.968 \\
\hline $\mathbf{2}$ & 22 & 22 & 0.205 \\
\hline $\mathbf{4}$ & 27 & 22 & 0.312 \\
\hline $\mathbf{6}$ & 25 & 17 & 0.009 \\
\hline $\mathbf{1 2}$ & 26 & 18 & 0.030 \\
\hline $\mathbf{2 4}$ & 23 & 15 & 0.010 \\
\hline
\end{tabular}

Mean $( \pm$ SD) VAS scores of TAP group (in mm) at $0,2,4$, 6,12 and 24 hours were $0.40( \pm 1.99), 22.42( \pm 12.53)$, $29.30( \pm 12.68), 31.24( \pm 15.78), 30.18( \pm 13.86)$ and 23.80 $( \pm 9.49)$ respectively and mean $( \pm$ SD) VAS scores of QLB group (in $\mathrm{mm}$ ) at $0,2,4,6,12$ and 24 hours were 0.36 $( \pm 4.26), 26.80( \pm 12.71), 22.04( \pm 11.22), 21.12( \pm 8.21)$, $22.84( \pm 8.47)$ and $16.84( \pm 6.43)$ respectively (Table 3$)$. Student $t$ test was applied. $\mathrm{P}$ value of $0.490,0.086,0.041$, $0.01,0.032$, and 0.01 were obtained for $0,2,4,6,12$ and 24 hours respectively. The mean VAS score at 12 hours was significantly higher in the TAP group compared to the QLB, $\mathrm{P}<0.05$ (Table 3).

35 patients in the TAP group and 31 patients in the QLB group required rescue analgesia. Mean $( \pm \mathrm{SD})$ time of first rescue analgesia required in TAP group and QLB group were $4.16 \pm 4.35$ hours and $6.03 \pm 3.70$ hours respectively (Table 4). A p value of 0.283 was obtained. There was statistically significant difference observed in the meantime of 1 st rescue analgesia required between these two groups.

$$
\begin{aligned}
& \text { Table 3: Mean }( \pm \mathrm{SD}) \text { VAS scores of TAP and QLB } \\
& \text { group. }
\end{aligned}
$$

\begin{tabular}{|llll|}
\hline $\begin{array}{l}\text { VAS } \\
\text { (hours) }\end{array}$ & Group TAP & Group QLB & P value \\
\hline $\mathbf{0}$ & $0.40(1.99)$ & $0.36(4.26)$ & 0.490 \\
\hline $\mathbf{2}$ & $22.42(12.53)$ & $26.80(12.71)$ & 0.086 \\
\hline $\mathbf{4}$ & $29.30(12.68)$ & $22.04(11.22)$ & 0.041 \\
\hline $\mathbf{6}$ & $31.24(15.78)$ & $21.12(8.21)$ & 0.010 \\
\hline $\mathbf{1 2}$ & $30.18(13.86)$ & $22.84(10.47)$ & 0.032 \\
\hline $\mathbf{2 4}$ & $23.80(9.49)$ & $20.84(8.43)$ & 0.050 \\
\hline
\end{tabular}

Table 4: Mean $( \pm \mathrm{SD})$ time of first rescue analgesia in TAP and QLB group.

\begin{tabular}{|lll|}
\hline Group & $\begin{array}{l}\text { Mean }( \pm \mathrm{SD}) \text { time } \\
(\text { hours })\end{array}$ & P value \\
\hline TAP group & $4.16(4.35)$ & 0.283 \\
\hline QLB group & $6.03(3.70)$ & \\
\hline
\end{tabular}

The mean $( \pm \mathrm{SD})$ dosage of rescue analgesia in TAP and QLB groups was $97 \pm 84.39$ and $91 \pm 88.54 \mathrm{mg}$ respectively. A p value of 0.643 was obtained. There was no statistically significant difference in the mean dose of rescue analgesia required between the two groups (Table 5). Only 2 patients in the TAP group experienced side effects such as nausea and vomiting whereas in the TAP group no side effects are seen (Table 6). A p value of 0.155 was observed.

Table 5: Mean $( \pm \mathrm{SD})$ dosage of rescue analgesia.

\begin{tabular}{|lll|}
\hline Group & Mean $( \pm \mathrm{SD})$ dosage $(\mathrm{mg})$ & P value \\
\cline { 1 - 2 } TAP group & $97(84.39)$ & 0.643 \\
\hline QLB group & $91(88.54)$ & \\
\hline
\end{tabular}

Table 6: Side effects in TAP and QLB groups.

\begin{tabular}{|lll|}
\hline TAP group & 2 (PONV) & P value \\
\hline QLB group & Nil & 0.155 \\
\hline
\end{tabular}

\section{DISCUSSION}

There are several modalities of regional techniques for post-operative analgesia in patients undergoing total abdominal hysterectomy under general anaesthesia. These include rectus sheath block, transversus abdominis plane block, inguinal herniorrhaphy blocks, quadratus lumborum block, lumbar paravertebral etc. Lumbar epidural are also commonly used. All of these blocks have their own set of technical difficulties and also side effects.

With the advent of the use of ultrasonography in the operating room there is renewed interest of use of regional techniques with or without catheters in all population subgroup (8) to find a simple yet safe technique. 
Our study showed that the patients who received the quadratus lumborum block had a greater analgesia in comparison with the transversus abdominis plane block. This was more pronounced at 6 hours post-surgery (mean VAS scores of 29.30 versus 22.04 at 4 hours, 31.24 versus 21.12 at 6 hours, 30.18 versus 22.84 at 12 hours, 23.80 versus 16.84 at 24 hours). Mean first rescue analgesia time for the TAP was 4.16 hours as against 6.03 hours for the QLB group. However the rescue analgesia remained similar between the two groups as most of the analgesia was administered early. In our study the initial VAS score remained the same. Hence TAP block was effective in the initial post-operative period. It was speculated that the analgesia after 24 hours may not be ascribed to the blocks as the drug action would have stopped by then.

The thoraco lumbar fascia is a covering of the back muscles. This along with the endothoracic fascia continues to the lumbar paravertebral space. The QLB block utilises this fascia for spread of local anaesthetic agents to the lumbar paravertebral region over psoas muscle major. This thus leads to a higher and longer concentration of local anaesthetic at the effector site. It is also assumed that it also effects the sympathetic nerves and the celiac ganglion via the splanchanic nerves. ${ }^{9,10}$ This is in sharp contrast to the TAP blocks which uses the plexus in between IO and TAP muscles for analgesia which may have a faster run off and thus shorter duration of action. ${ }^{11}$

Our results varied from the study carried out by Blanco et al for post op analgesia in post caesarean patients as the analgesia effected by the quadratus lumborum block was more effective after 6 hours and had marked difference after 12 hours. The study by Blanco studied analgesia immediate post op analgesia extending to beyond 24 hours and reported a superior analgesia throughout the observation period. This was ascribed to greater action by QLB by spread of local anaesthetic into the thoracolumbar plane which has a higher density of alpha efferents as well as sympathetic fibres. ${ }^{12}$

Our results were similar to a study by Yousef who showed a marked analgesia in patients who received QLB in comparison with TAP Block in patients undergoing hysterectomy. ${ }^{13}$ However, in our study the initial VAS scores and total analgesic requirements were similar in the two groups.

A study by Verma et al in 2019 showed a higher time for rescue analgesia for QL in comparison with TAP group in patients undergoing caesarean section (CS) (mean \pm SD: $68.77 \pm 1.74$ hour versus $13.3 \pm 1.21$ hour $)(p<0.001) .{ }^{14}$ The QL group had significantly less analgesic demand $(\mathrm{p}<0.001)$ at $2,4,6,12,24,36,48$ and 72 hour post-CS. In contrast with our study the VAS at rest and movement was significantly reduced in the QL group at all times in comparison with the study by Verma et al.

A study by Carney et al demonstrated that the abdominal regions corresponding to the dermatomal segments of $\mathrm{T} 4$ to L2 were covered by a single shot QLB, and the authors also proved that injected radiolucent material accumulated at lateral border of quadratus lumborum then spread in the posterior cranial fashion to the anterior aspect of the QL and psoas major to the paravertebral space. ${ }^{15}$ Higher blood levels of local anaesthetic levels in TAP block reducing efficacy were also shown by Muruchi et al. ${ }^{16}$

Our results were similar to Okuz et al who compared TAP block and QLB in paediatric patients undergoing lower abdominal surgery and reported that TAP block group showed significantly higher post-operative FLACC scores than QLB group $(\mathrm{p}<0.05)$. The number of patients who received rescue analgesia in the first day after surgery was significantly higher in the TAP block group in contrast with QLB group $(\mathrm{p}<0.05)$. Parent's satisfaction scores were lower in TAP block group than in QLB group. ${ }^{17}$

Our study results were similar to results published by Baidya et al who showed that a single injection QL block between QL and psoas major in lateral position in children undergoing pyeloplasty and reported good analgesia throughout post-operative period. ${ }^{18}$

Our study has shown a distinct advantage of QLB over TAP even though it may have significant after 6-12 hours after surgery. But the QLB can be administered just as easily as the TAP. There is thus a need to shift to these blocks for abdominal surgeries including TAH. They can also be administered continuously with a catheter thus obviating the need of epidurals yet increasing the safety and patient comfort.

\section{Limitations}

The study though randomised was not a blinded study which is a limitation of this study. The sample size was small to generalise the findings to a population. Both these blocks have been used for lower abdominal surgery only.

\section{CONCLUSION}

In patients undergoing abdominal hysterectomy quadratus lumborum block may be preferred over transversus abdominis plane block for post-operative analgesia.

Funding: No funding sources

Conflict of interest: None declared

Ethical approval: The study was approved by the Institutional Ethics Committee

\section{REFERENCES}

1. Preeti RH, Chothani C, Gupta SD. Predictors of hysterectomy amongst married women 15-49 years in India. Reprod Health. 2018;15(1):3.

2. Nirboer TE, Johnson N, Lethalry A, Tevender E, Curr E, Garry R, et al. Surgical approach to hysterectomy for benign gynaecological diseases. Cochrane Database Syst Rev. 2009;3:CD003677. 
3. Wilmore DW, Kehlel H. Management of patients in fast track surgery. BMJ. 2001;322:473-6.

4. Jorgenson H, Formsgaardd JS, Dirk J, Wetterler J, Andreasson B, Dall JB. Effect of peri and postoperative epidural anaesthesia on pain and GI function after abdominal hysterectomy. $\mathrm{Br} \mathrm{J}$ Anaesth. 2001;87(4):577-83.

5. Corney JJ, Mc Donell JG, Ochana A, Bhinder R, Laffey JG. The transversus abdominis plane block provides effective post-operative analgesia in patients undergoing total abdominal hysterectomy. Anaesthesia. 2008;107:2056-60.

6. Belavy D1, Cowlishaw PJ, Howes M, Philips F. Ultrasound guided transversus abdominis plane block for analgesia after Caesarean delivery. Br J Anaesth. 2009;103(5):726-30.

7. Blanco R. TAP block under ultrasound guidance: The description of a "non-pops technique". Reg Anaesth Pain Med. 2007;32:130.

8. Aksu C, Gurkan Y. Ultrasound guided Quadratus Lumborum Block for post-operative analgesia in pedriatic ambulatory inguinal hernia repair. J Clin Anaesth. 2018;46:77-8.

9. Akerman MI, Pejcic NZ, Velickovic I. A review of the quadratus lumborum block and ERAS. Front Med (Lausanne). 2018;26(5):44.

10. Elsharkawy H, El-Boghdadly K, Kolli S. Injectate spread following anterior sub-costal and posterior approaches to the quadratus lumborum block. Eur J Anaesthesiol. 2017;34:587-95.

11. Chakarborty A, Goswami J, Patro V. Ultrasound guided continuous quadratus lumborum block for post-operative analgesia in paedriatic patient. Anaesth Analgesia. 2015;4:34-6.

12. Blanco R, Ansari T, Riad W, Shetty N. Quadratus lumborum block versus Transversus abdominis block for post operative pain after Caserean delivery : A randomized controlled trial. Reg Anaesth Pain Med. 2016;41:757-62.
13. Yousef NK. Quadratus lumborum Block versus Transversus Abdominis plane Block in Patients Undergoing total Abdominal Hysterectomy: A randomized Prospective Controlled Trial. Anesth Essays Res. 2018;12(3):742-7.

14. Verma K, Malawat A, Jethava D, Jethava DD. Comparison of transversus abdominis plane block and quadratus lumborum block for post-caesarean section analgesia: A randomised clinical trial. Indian $\mathbf{J}$ Anaesth. 2019;63:820-6.

15. Carnney J, Finnerty O, Rauf J, Bergin D, Laffey JG, McDonnell JG, et al. Studies on spread of local anaesthetic solution in transversus abdominis plane blocks. Anaesthesia. 2011;66:1023-30.

16. Mourouchi T, Iwasaki S, Yamakage $M$. Chronological changes in ropivacaine concentration and analgesic effects between transversus abdominis plane block and rectus sheath block. Reg Anesth Pain Med. 2015;40:568-71.

17. Oksuz G, Bilal B, Gurukan Y, Urfalioglu A, Arslan M, Gigi G, et al. Quadratus lumborum block versus transversus abdominis plane block in children undergoing lower abdominal surgeries: A randomized controlled trial. Reg Anesth Pain Med. 2017;42:6749.

18. Baidya DK, Maitra S, Arora MK, Agarwal A. Quadratus lumborum block: An effective method of Perioperative analgesia in children undergoing Pyeloplasty. J Clin Anesth. 2015;27:694-6.

Cite this article as: Gupta SK, Grewal R, Anne S, Garg A. A comparison of transversus abdominis plane block with quadratus lumborum block for postoperative analgesia in abdominal hysterectomy: a retrospective observational study. Int J Reprod Contracept Obstet Gynecol 2021;10:1814-9. 